\title{
SUMBANGSIH FILSAFAT ESENSIALISME BAGI PENDIDIKAN AGAMA KRISTEN
}

\section{Noh Ibrahim Boiliu}

\section{ABSTRAK}

Pendidikan Agama Kristen (PAK) tidak dapat berdiri sendiri, ia juga dipengaruhi oleh disiplin ilmu lain atau membutuhkan kolaborasi dengan ilmu lain, salah satunya yaitu dari filsafat Esensialisme. Pengaruhnya nyata di dalam proses belajar dan mengajar PAK. Commond groundnya atau titik pertemuannya adalah dalam prinsip dasar esensialisme yaitu: 1) tugas pertama sekolah adalah mengajarkan pengetahuan dasar; 2) belajar adalah pekerjaan yang berat dan butuh disiplin; 3) Pendidik adalah wadah atau tempat dari otoritas kelas. Oleh sebab itu, sumbangsih filsafat esensialisme terhadap PAK dapat dilihat melalui: 1) Kurikulum; 2) Manajemen kelas; 3) Metode; 4) Pendidik; 5) Penilaian.

Kata-Kata Kunci: Esensialisme, Pendidikan, Pendidikan Agama Kristen (PAK).

\section{Latar Belakang Filsafat Esensialisme}

Esensialisme adalah pandangan bahwa, untuk setiap entitas tertentu (seperti binatang, sekelompok orang, benda fisik, konsep), ada satu set atribut yang diperlukan untuk identitas dan fungsinya. Dalam pemikiran Barat, konsep ini ditemukan dalam karya Plato dan Aristoteles.

Dalam membahas esensialisme pendidikan, maka harus dimengerti dua aliran filsafat pembentuk. Esensialisme membangun fondasi filosofisnya di atas idealisme dan realisme. Oleh karena itu, sebelum membahas esensialisme maka penting untuk membahas idealisme dan realisme.

\section{Dua Aliran Filsafat Pembentuk Esensialisme: Idealisme dan Realisme}

Berikut penjelasan filsafat idealisme dan realisme sebagai dasar bagi filsafat esensialisme. Kedua aliran filsafat inipun ikut mempengaruhi teori pendidikan esensialis (idealis dan realis). Dengan mengetahui peran 
kedua aliran filsafat ini, maka setidaknya dapat membantu dalam memahami filsafat esensialisme baik dalam konteks filosisnya (sejarah dan isi) maupun dalam kaitannya dengan teori pendidikan.

\section{Idealisme}

Idealisme"1 Platonis adalah teori awal yang dikenal yakni bagaimana semua hal yang diketahui dan konsep memiliki realitas penting di belakang mereka (sebuah "Ide" atau "Form"), esensi yang membuat halhal dan konsep apa yang mereka. Dalam filsafat idealisme Plato, Plato memandang ide sebagai yang tidak diciptakan manusia, berdiri sendiri (tidak bergantung pada manusia), objektif, dan idea-lah yang memimpin manusia. Bahkan tiap manusia memiliki ide yang berbeda dan dengan cara yang berbeda dalam pengungkapannya. "Plato sangat menghargai kemungkinan-kemungkinan yang terdapat dalam akal manusia dan ia bermaksud menolong sesamnya berpikir rasional". ${ }^{2}$ Dalam sudut pandang perbedaan pengungkapan ide inilah, dan dalam sudut pandang pendidikan, pendidik harus jeli mengenali setiap peserta didik sehingga membantu mereka dalam mengungkapkan ide dalam kreatifitas anak didik. Pendidik harus dilihat sebagai "sesama" yang menolong "sesama" untuk berpikir rasional. Ini berarti pendidik harus "melatih". ${ }^{3}$

Plato adalah salah satu essentialists pertama, percaya pada konsep bentuk yang ideal, suatu entitas abstrak yang objek individu yang hanya faksimil. Untuk memberikan contoh; bentuk ideal dari lingkaran adalah lingkaran sempurna, sesuatu yang secara fisik tidak mungkin untuk membuat nyata, namun lingkaran yang ditarik dan mengamati jelas memiliki beberapa ide yang sama - ide ini adalah bentuk yang ideal. Plato percaya bahwa ide ini adalah kekal dan jauh lebih unggul dari manifestasi mereka di dunia, dan bahwa manusia memahami manifestasi ini dalam

${ }^{1}$ Harun, Hadiwijono, Sari Sejarah Filsafat Barat 1 (Jakarta: Kanisius, 1980), 40. Dalam konsep idea (lisme) Plato, Plato dapat menjembatani filsafat Heraklitos (pemberhentian dengan filsafat Parmenides (menyangkal gerak dan perubahan).

2 Robert R. Boehlke, Sejarah Perkembangan pemikiran dan Praktek Pendidikan Agama Kristen. Dari Plato sampai Ig. Loyola (Jakarta: BPK Gunung Mulia, 2011), 7.

3 Ibid. Plato menolak kegiatan melatih sebagai pendidikan. Sebab pendidikan menyangkut manusia seutuhnya. 


\section{SUMBANGSIH FILSAFAT EKSISTENSIALISME BAGI P.A.K. 27}

dunia materi dengan membandingkan dan mengaitkannya dengan bentuk yang ideal masing-masing.

Sebagai founder dari idealisme, Plato 4 juga konsen pada pendidikan bahkan banyak penulis secara ekstensif menulis tentang hal tersebut. Plato menjadikan pendidikan sebagai karya inti dalam "utopia state, the Republic". Oleh karenanya, Augustinus kemudian mengadopsi pemikiran Plato dengan memberikan perhatian yang besar, baik berkaitan dengan "idealisme dan agama"5 maupun idealisme dan pendidikan. "Augustine gave extensive attention to the need for Christian to become aware for the importance of education". 6

Jadi, penekanan dari idealisme adalah bahwa gagasan merupakan hal inti atau akal sebagai hal terdahulu dan masalah-masalah yang muncul merupakan hasil dari akal. Hal ini mungkin seperti ungkapan dari Butle, "when we speak of the mind unless we are more exat in our terms that most people, we are porbably referring to the brain. Sometimes we speak of using our brains or using our heads. When we really mean using our minds".' Apa yang dikatakan Butle adalah sesungguhnya berbicara tentang realitas diri dari manusia. Sebab ketika berbicara tentang "pikiran" apakah manusia menggunakan otak ataukah kepala. Ini merupakan contoh bahwa aktifitas berpikir sebagai realitas dari manusia. Karena "akal dan gagasan"s sebagai penekanan dari idealisme. Atau, bahwa "kenyataan bagi seorang kamu dikotomus-terdapat dunia dari apa yang terlihat, yang dirasakan melalui perasaan kita, dan dunia realitas, yang dirasakan melalui akal kita". ${ }^{9}$ Sebab

4 Howard A. Ozman \& Samuel L. Craver, Philosophical Foundation of Education (USA: Merril Publishing Company, 2010), 15.

${ }^{5}$ Untuk bagian idealism dan agama dapat dibaca dalam, J. Donald Butler, Four Philosopies. And Their Practice in Education and Religion (New York: Harper and Brothers Publisher, 1957), 263-286, dengan judul bab Idealism in Religion.

${ }^{6} \mathrm{Ibid}$.

7 J. Donald Butle, Idealism in Education (New York: Harper \& Row Publishing, 1966), 40

8 George R. Knight, Isu-isu dan Alternatif dalam Filosofi Pendidikan, terj, (Bogor: Yayasan Kasih Abadi, 2006), 39

${ }^{9}$ Ibid. Bandingkan dengan Gerald L. Gutek in Historical and Philosophical, h. 17-18, The objects that we sense-see, touch, smell, and hear-are imperfect representations of the perfect ideas of these objects located in the general form of the good. 
" all ideas comes from a superior, higher, and all-encompassing idea, called the form of good'10 atau dunia akal berfokus pada ide (lisme) atau gagasan.

Idealisme dan Pendidikan

Seperti yang diuraikan di atas bahwa konsep ide dan filsafat idealisme berakar pada pemikiran Plato tentang teori gua atau yang disebut ide. Dan dalam kaitannya dengan pendidikan, Noddings melihat model pendidikan Plato sebagai model fungsional, 'Plato's model of education is functionalist-a model designed to produce competent adults to meet the needs of the state. Plato developed his thought on education in the context of describing the ideal state...". ${ }^{11}$ Model fungsionalis didesain agar dapat membantu setiap orang (dewasa) menemukan kemampuan-kemampuan sesuai minat mereka (ingat: tekanan filsafat Plato adalah bahwa setiap orang memiliki kemampuan yang berbeda-beda).

Untuk mengenali idealisme dalam pendidikan maka dapat dilihat pada hal-hal seperti berikut ini:

1) Tujuan pendidikan: bahwa tujuan pendidikan idealisme adalah tidak hanya menekankan pembangunan pikiran (development of the mind) yakni mecari gagasan-gagasan yang benar (true of ideas) tetapi juga fokus membimbing peserta didik berkaitan dengan nilai akhir (lasting value) yakni membangun karakter atau "character development". ${ }^{2}$ Ozman dan Craever juga mengatakan bahwa hal inipun ditekankan oleh Kant, bahwa seorang peserta pendidik tidak hanya "knowledgeable but the good person". ${ }^{3}$ Knight menyebutnya "menjadi pribadi yang sempurna". ${ }^{14}$

2) Sekolah dan pendidik: bagi aliran idealis, pengajar mempunyai posisi yang sangat penting di mana pendidik melayani peserta pendidik sebagai teladan hidup dari apa yang dilakukannya. Pendidik bukan yang sedang belajar tentang hal yang diajar sehingga ia mampu

10 Geral L. Gutek, Historical and Pbilosophical Foundations of Education. A Bigraphical Introduction. Second Edition, (Ohio: Macmillan Publishing Company, 2010), 17.

${ }^{11}$ Nel Noddings, Philosophy of Education (USA: Westview Press, 2010), 10.

${ }^{12}$ Ozman \& Samuel L. Craver, Philosophical Foundation.

13 ibid .

${ }^{14}$ Knight, Isu-isu, 43. 


\section{SUMBANGSIH FILSAFAT EKSISTENSIALISME BAGI P.A.K. 29}

membuat pertimbangan. Hal ini juga dikemukakan oleh Butler bahwa "pendidik adalah pusat pendidikan" meski disadari bahwa mungkin ini merupakan bagian yang akan menjadi sasaran kritik. Namun kaum idealist beragumentasi bahwa bagaimana mungkin tidak bahwa pendidik adalah pusat. Sebab peserta pendidik itu "kosong". Pendidik merupakan "kunci" dalam pembelajaran sebab ia dapat membuat batasan-batasan:

the teacher is central in the idealist pattern of education. Not, of course, because the teacher is all and the students are nothing; that is bad pedagogy from standpoint of idealism... but rather, because the teacher is more the key to the eucative process than any other element comprasing it He is the sungular position of determining what the students oppurtinities for learning and growing shall be. ${ }^{15}$

Dalam perspektif idealisme, pendidik dipandang sebagai:

"the personification of reality for the child, be a specialist in the knowledge of pupils, be an excellent technician, be a personal friend of the individual student, be the kind of person who commands the respect of the pupil by virtue of what he himself is, be a person who awakens in the pupil the desire to learn, be a master of the art of living, be a coworker with God in perfecting man, be one who capably communicates his subject."16

3) Kurikulum: berkaitan dengan kurikulum, kaum idealis dalam pendidikan adalah mereka melihatnya dari posisi epistemologinya-the subject matter of idealism is viewed in term of its espistemological position". ${ }^{17}$ Dan bahwa jika kebenaran adalah gagasan-gagasan maka kurikulum harus dibentuk di sekitar persoalan-persoalan yang membawa ke dalam hubungan gagasan-gagasan tersebut. Maka tidak heran jika mereka menekankan kurikulum ada studi tentang kemanusian

Realisme

Realisme adalah aliran filsafat yang memandang bahwa dunia materi diluar kesadaran ada sebagai suatu yang nyata dan penting untuk kita

15 J. Donald Butler, Four Philosopies. And Their Practice in Education and Religion (New York: Harper and Brothers Publisher, 1957) 240.

${ }^{16}$ Ibid., 241-243.

17 George R. Knight, Philosophy and Education. An introduction in Christian Persective (Michigan: Andrews University Press, 1980), 49. 
kenal dengan mempergunakan intelegensi. Objek indra adalah real/nyata, yaitu benda-benda ada, adanya itu terlepas dari kenyataan bahwa benda itu diketahui, atau dipersepsikan atau ada hubungannya dengan pikiran manusia. Menurut realisme, hakikat kebenaran itu berada pada kenyataan alam ini, bukan pada ide atau jiwa. Zat merupakan dasar segala benda, yang disebut aristoteles asas potensial karena zat itu bisa menjadi apa saja. Zat dan bentuk harus dipisahkan. Akan tetapi dalam dunia ini, keduanya tidak dapat dipisahkan. Menurutnya dunia bukanlah yang samar tetapi nyata dan alami oleh manusia.

Aristoteles adalah lebih realis, dalam arti modern, dari pada pendidiknya, Plato. Aristoteles merupakan seorang filosuf pertama. Ia menciptakan cabang pengetahuan itu dengan menganalisis problemproblem tertentu yang timbul dalam hubungannya dengan penjelasan ilmiah. ${ }^{18}$ Ia mempunyai bakat mengatur cara berpikir serta merumuskan kaidah dan jenis-jenisnya yang kemudian menjadi dasar berpikir dalam banyak bidang ilmu pengetahuan. Ia tak pernah terjeblos dalam rawarawa mistik ataupun ekstrem. Ia senantiasa bersiteguh mengutarakan pendapat-pendapat praktis. ${ }^{19}$

Real berarti yang aktual atau yang ada, kata tersebut menunjuk kepada benda-benda atau kejadian-kejadian yang sungguh-sungguh, artinya yang bukan sekadar khayalan atau apa yang ada dalam pikiran. Real menunjukkan apa yang ada. Realitas adalah keadaan atau sifat benda yang real atau yang ada, yakni bertentangan dengan yang tampak. Dalam arti umum, realism berarti kepatuhan kepada fakta, kepada apa yang terjadi, jadi bukan kepada yang diharapkan atau yang diinginkan. Akan tetapi dalam filsafat, kata realisme dipakai dalam arti yang lebih teknis.

Dalam arti filsafat yang sempit, realisme berarti anggapan bahwa objek indra manusia adalah real, benda-benda ada, adanya itu terlepas dari kenyataan bahwa benda itu diketahui, atau dipersepsikan atau ada hubungannya dengan pikiran manusia. Bagi kelompok realis, alam itu, dan satu-satunya hal yang dapat dilakukan adalah: menjalin hubungan yang baik dengannya. Kelompok realis berusaha untuk melakukan hal ini,

${ }^{18}$ Imron. S.Ag. M.A, Filsafat Umum (Palembang: Noer Fikri Offset, tt), 5657

${ }^{19}$ Wahyu Murtiningsih, Para Filsuf dari Plot Sampai Ibnu Baijah (Yogyakarta: IRCiSoD), 56. 
bukan untuk menafsirkannya menurut keinginan atau kepercayaan yang belum dicoba kebenarannya. Seorang realis bangsa Inggris, John Macmurray mengatakan: manusia tidak bisa melepaskan diri dari fakta bahwa terdapat perbedaan antara benda dan ide. Bagi common sense biasa, ide adalah ide tentang sesuatu benda, suatu fikiran dalam akal manusia yang menunjuk suatu benda. Dalam hal ini, benda adalah realitas dan ide adalah 'bagaimana benda itu nampak pada kita'. Oleh karena itu, maka fikiran harus menyesuaikan diri dengan benda-benda, jika mau menjadi benar, yakni jika ingin agar ide manusia menjadi benar, jika ide manusia tersebut cocok dengan bendanya, maka ide itu salah dan tidak berfaedah. Benda tidak menyesuaikan dengan ide manusia tentang benda tersebut. Manusia harus mengganti ide-idenya dan terus selalu menggantinya sampai didapatkan ide yang benar. Cara berpikir common sense semacam itu adalah cara yang realis; cara tersebut adalah realis karena ia menjadikan 'benda' adalah bukan 'ide' sebagai ukuran kebenaran, pusat arti. Realisme menjadikan benda itu dari real dan ide itu penampakkan benda yang benar atau yang keliru

\section{Filsafat Esensialisme dalam Pendidikan Kristen}

Di setiap bidang studi keilmuan, pasti dicari landasan berpikir filosofisnya. Termasuk di dalamnya pendidikan. Filsafat pendidikan yang dianut akan memberikan arah bahkan sebagai metode pendekatan dalam mencari arah ke tingkat penerapan. Menurut Peterson:"The philosophy of education is the attempt to bring the insights and methods of philosophy to bear on the educationed enterprise". ${ }^{20}$ Teori dapat menjadi titik berangkat menuju aktifitas penerapan. Kedua wilayah ini, teori-praktek menjadi bagian penting, "these two dimensions of philosophy have an impact on educational theory at key point... as a subject matter (metaphysics and epistemology) and as an activity (this is the intellectual functions: syntetic, analytic, descriptive, and normative)". ${ }^{21}$ Dalam konteks ini, sangat penting filsafat (pendidikan) dalam membangun teori pendidikan. Sebab, sejak sebuah teori pendidikan dibangun, maka akan dapat dimengerti filsafat apa dibalik teori tersebut. Dalam prosesnya (pendidikan), kita dapat memahaminya sehingga akhir

${ }^{20}$ Michael L. Peterson, Philosophy of Education. Issues and Option, (Illionis: InterVarsity Press, 1999), 17.

${ }^{21}$ Ibid., 18-22. Bandingkan dengan, George F. Keneller, Introduction to the Philosophy of Education, 1-2. Kneller menyebutnya "three modes of philosoph. Speculative, prescriptive, and the analytic. 
dari teori tersebut apakah dapat membangun nilai, baik di tingkat personal maupun masyarakat umum. Tentu ini berkaitan dengan pengaruh pendidikan terhadap pribadi dan masyarakat. Hal senada juga diungkapkan oleh Maritain dalam esainya, "Thomist Views on Education", 22 bahwa ada hubungan bahkan pengaruh antara "education and the individual", 23 "school and society", ${ }^{24}$ school and religion". ${ }^{25}$

Filsafat dan pendidikan merupakan dua term saling terkait ketika kita membicarakan filsafat pendidikan. Tidak dapat dinafikan bahwa filsafat pun berkonsentrasi dengan teori. "Philosophy is primarily concerned with theory, the examination of ideas and ideals. Ideas about the meaning of the buman venture, of the existence of God, the nature of knowledge, the principles of morality..."26 Dalam hal ini, para pengajar profesional harus menyadari bahwa berpikir logis-analitik adalah sangat penting. Di sinilah, penting filsafat dapat membangun konsep dimaksud.

\section{Kurikulum, Metode, Pendidik, Manajemen Kelas, dan penilaian dalam Sudut Pandang Esensialis}

Munculnya esensialisme sebetulnya merupakan reaksi terhadap "progresifisme"27 yang dianggap terlalu "halus". Mungkin hal ini

${ }^{22}$ Nelson B. Henry (ed), Modern Philosophies and Education. The Fifty-fourth Year Book of the Natioal Society for the Study of Education, part I (Illionis: University of Chichago Press, 1960), 57-90.

23 Ibid., 70. Maritain mengangkat kembali pemikiran Aquinas ars co-operativa naturae. Pengaruh ini adalah bahwa peserta pendidik akan berubah dengan adanya pendidikan. Jika demikian, dalam desain kurikulum, kurikulum tidak didesain untuk pendidik melainkan peserta pendidik. Itulah yang dikutip oleh Maritain dari Thomas Aquinas, the principal agent in the educational process is not teacher nut the student.

${ }^{24}$ Ibid., 72.

25 Ibid., 83. Maritain melihat hal ini pada tingkat pendidikan moral dan agama (moral education and religion). Pada point about God and the relation of man to Godching of theology, ia mengatakan bahwa "truth to be known about and relation of man to God matters more to religious faith than human action to regulated.

${ }^{26}$ Michael L. Peterson, Philosophy of Education. Issues and Options (Illionis: InterVarsity Press, 1999), 17.

${ }^{27}$ Reaksi tersebut berkenaan dengan anggapan dari esensialisme bahwa progresifisme terlalu halus. Progresifisme lebih menekankan pendidikan yang 


\section{SUMBANGSIH FILSAFAT EKSISTENSIALISME BAGI P.A.K. 33}

berkaitan dengan prinsip pendidikan. Hal ini dapat dilihat dari prinsip pendidikan yang diberlakukan esensialis yakni kerja keras dan disiplin dalam belajar.

Esensialisme merupakan aliran filsafat yang muncul dari pertemuan idealisme $^{28}$ dan realisme ${ }^{29}$ (perhatikan bagan Knight). Tidak mungkin

berwawasan humanis dengan model sekolah bebas yakni kelas terbuka, dan sekolah bebas.

28 Perhatikan catatan Knight tentang idealisme pada halaman 39-50. Idealisme dalam tataran filosofisnya lebih merupakan suatu metafisika, di mana akal sebagai suatu realitas ada. Maka segi epistemologinya adalah apakah realitas "akal" sebagai ada tadi dapat diketahui atau tidak. Jika ya maka apakah mentodenya; bahkan jika sudah diketahui realitas dari akal, maka apa manfaatnya (aksiologis). Jika tidak bermanfaat maka tidak berfungsi (bandingkan dengan tiga alam pikiran yang dikemukakan van Peursen dalam strategi kebudayaan. Di mana alam pikir ketiga adalah tahap fungsionalis. Dapat membacanya dalam buku Strategi Kebudayaan). Di sisi aksilogis inilah titik tolak pragmatisme.

Idealisme pun sebetulnya menemukan kekuatannya dalam pemikiran Imanuel Kant. Kant juga sebenarnya memadukan dua pemikiran yang sebelumnya menjadi pokok perdebatan antara kaum rasionalis (Rene Deskartes dengan semboyan Cogito Ergo Sum juga Cogito Aliquid) dengan kaum empiris (John Locke, David Hume, Francis Bacon, dll). Dari sini jugalah, analisis-analisis deduktivis dan induktivis. Yang kemudian hari diadopsi teologi yang mana digunakan dalam ilmu herneneutika dan secara teknis digunakan dalam tafsir.

Dalam hubungannya, idealisme-pendidikan, kaum idealis melihat manusia sebagai perluasan dari pribadi individu yang sempurna; kesempurnaan sebagai orientasi. Apapun yang dikerjakan, maka akan dikerjakan sejauh "mereka" dapat. Bagi kaum idealis, pengajar adalah pribadi yang dengan dunia kesempurnaan pengetahuan.

${ }^{29} \mathrm{~J}$. Donald Butler, Four Pbilosopies. And Their Praktice in Education and Religion (New York: Harper \& Brothers Publisher, 1957), 344. Konsentrasi filsafat realisme adalah "to see in what way the rationale of the school is conceived by realists. Dalam konteks ini, John Amos Comenius berkata "man is not made a man only by his biological birth. If he is to be made a man, buman culture must give direction and form to his basic potentialities. Realisme vs Idealisme; kebebasan berpikir vs abstraksi; Aristoteles vs Plato (peserta pendidik vs pendidik); universalitas vs individualitas. Di sinilah pemikiran John Locke tentang teori tabula rasa (pikiran adalah sebuah lembaran kosong) dan Anda akan menerima pengaruh dari lingkungan. Dalam tataran, akal - realitas; realitas - akal inilah idealisme dan realisme bersebrangan. Idealisme memandang akal sebagai realitas (realitas ada di dalam akal) sedangkan realis memandang kehidupan manusialah yang 
mengerti esensialisme tanpa memahami dua aliran pembentuk esensialisme. Idealisme ${ }^{30}$ dan realisme $^{31}$ adalah aliran filsafat yang membentuk corak "esensialisme". ${ }^{32}$ Dua aliran ini bertemu sebagai pendukung esensialisme, akan tetapi tidak lebur menjadi satu dan tidak melepaskan sifatnya yang utama pada dirinya masing-masing.

Dengan demikian Renaissance adalah pangkal sejarah timbulnya konsep-konsep pikir yang disebut esensialisme, karena itu timbul pada zaman itu, esensialisme adalah konsep meletakkan sebagian ciri alam pikir modern. Esensialisme pertama-tama muncul dan merupakan reaksi terhadap simbolisme mutlak dan dogmatis abad pertengahan. Maka, disusunlah konsep yang sistematis dan menyeluruh mengenai manusia dan alam semesta, yang memenuhi tuntutan zaman.

Sebagaimana aliran-aliran filsafat sebelumnya seperti idealisme, realisme, pragmatisme, progresivisme dan lain-lain yang memiliki pandangan tentang pendidikan, aliran esensialisme juga memiliki pandangan yang berkaitan dengan pendidikan. Secara umum, persoalan pendidikan yang disoroti oleh aliran esensialisme adalah bagaimana sebenarnya tujuan pendidikan yang ideal? Bagaimana konsep kurikulumnya? Apa peran pendidik dan sekolah untuk memersiapkan subjek didik yang diinginkan oleh penganut esensialime?

Seperti progresivis dan "perenealis"33, esensialis menurut beberapa pakar tidak memiliki akar filosofis yang tunggal, "essentialist, unlike

membentuk kenyataan. Di siniah diperoleh pengertian epistemologi dari realisme yakni kebenaran melalui observasi dengan memanfaatkan metode induktif (bandingkan Metode Kuantitatif dan kualitatif). Bahkan dikemudian hari beralih pada teori korespondensi (misalnya, apakah benar bahwa bahasa Roh mempengaruhi kelakuan peserta pendidik).

${ }^{30}$ Bandingkan dengan,J. Donald Butle, Idealism in Education (New York: Harper and Row Publishers, 1966).

${ }^{31} \mathrm{Wm}$. Oliver Martin, Realism in Education (New York: Harper and Row Publishers, 1969).

${ }^{32}$ George R. Knight, Philosophy and Education. An Introduction in Christian Perspective (Michigan: Andrews University Press, 1980), 108.

33 Perenealis sebetulnya mengusung semangat middleness dan merupakan reaksi terhadap progresifis yang humanis (seperti eksistensialis). Konsep pendidikan perenealis adalah pendidikan liberal. Liberal di sini tidak seperti yang 


\section{SUMBANGSIH FILSAFAT EKSISTENSIALISME BAGI P.A.K. 35}

progresives and perennealists, do not have a singular philosophic base". ${ }^{34}$ Melainkan mendasarkan teorinya pada idealisme dan realisme. Namun, keduanya sama di dalam fokus yang berfokus pada proses pendidikan - "like perenealism, essentialism stands for the reinstatement of subject matter at the center of the educational process". 35

Munculnya esensialisme karena di Amerika pada era 1930-an berkembang progresifisme. Pada intinya esensialisme ingin mengingatkan rakyat Amerika bahwa, pertama, "who feel that the schools have 'gone to pot' atau sekolah-sekolah telah mengalami kemunduran" dan kedua, "Since the 1930s the essentialists have put forth a great deal of effort to warn the American public of "life-adjustment education, the child centered school and deterioration of learning in the United States". 36 Reaksi esensialis boleh juga dilihat sebagai bentuk kritik atas pendidikan progresifis. Esensialis justru mengkampanyekan gerakan "kerja keras dan disiplin" untuk mengatasi kemunduran pendidikan di Amerika.

Dengan adanya gerakan esensialisme, maka dapat katakan bahwa esensialisme memporklamirkan revolusi belajar dan proses pendidikan yakni pada bekerja keras dan disiplin belajar. Dalam hal ini, kurikulum, metode belajar, manajemen kelas, pendidik menjadi fokus esensialisme.

\section{Kurikulum dan Manajemen Kelas (Curriculum and Mangement Classroom)}

Dalam konteks peran pendidik, Pazmiño mengatakan bahwa "para pendidik yang menganut filsafat esensialisme menekankan keunggulan akademis, penguatan intelek, serta transmisi dan asimilasi dari sekaian mata pelajaran yang wajib sifatnya". ${ }^{37}$ Ini berarti dalam desain kurikulum para desainer akan benar-benar menyadari (konteks filsafat esensialisme) hal apa yang akan ditekankan dan dari segi marketing, hal yang

dipahami pada umumnya yang bertendensi "negatif dalam konteks teologi". Melainkan ke arah pendidikan sekuler.

${ }^{34}$ Knight, Philosophy and education, 108.

${ }^{35}$ George F. Kneller, Introduction to the Philosopby of Education ( New York, London: John Wiley Inc, 2010), 57.

36 Ibid.

${ }^{37}$ Robert W. Pazmini, Fondasi Pendidikan Kristen ( Jakarta: BPK Gunung Mulia-STT Bandung, 2012), 159. 
diunggulkan itu ditawarkan. Dengan kata lain, out put sudah "terbayangkan" ketika kurikulum didesain. Pembayangan itu (futurist) bukan tanpa alasan sebab telah tergambar melalui desain kurikulum. Dengan demikian out put seperti apa sudah terbayangkan.

Esensialis percaya bahwa ada inti umum pengetahuan yang perlu sampaikan kepada siswa dalam cara yang sistematis dan penuh disiplin. Penekanan dalam perspektif konservatif ini adalah pada standar intelektual dan standar moral yang mana sekolah harus mengajar. Inti dari kurikulum ini adalah pengetahuan penting dan keterampilan dan kekakuan akademis. Meskipun filsafat pendidikan ini mirip dalam beberapa cara untuk Perennialism, Essentialists menerima gagasan bahwa kurikulum inti ini dapat berubah. Sekolah harus praktis, mempersiapkan siswa untuk menjadi anggota masyarakat yang berharga. Ini harus fokus pada fakta-realitas objektif di luar sana - dan "dasar-dasar," pelatihan siswa untuk membaca, menulis, berbicara, dan menghitung dengan jelas dan logis. Sekolah tidak harus mencoba untuk mengatur atau mempengaruhi kebijakan. Siswa harus diajarkan sikap kerja keras, menghormati otoritas, dan disiplin. Pendidik harus membantu siswa menjaga naluri non-produktif mereka dicek, seperti agresi atau kecerobohan.

William C. Bagley, salah satu tokoh esensialis berkata bahwa

Essentialists hope that when students leave school, they will possess not only basic skills and an extensive body of knowledge, but also disciplined, practical minds, capable of applying schoolhouse lessons in the real world. ${ }^{38}$

Intinya adalah bahwa kurikulum esensialis mempersiapkan siswa untuk mempelajari dan mengetahui pengetahuan-pengetahuan dasar setelah itu baru melanjutkan ke tahap yang lebih tinggi. Hal ini pun akan terlihat dalam desain kelas esensialis. Matheney melalui blog-nya mengungkapkan bahwa:

Essentialists urge that the most essential or basic academic skills and knowledge be taught to all students: Traditional disciplines

${ }^{38}$ http:/ / education101intrototeaching.pbworks.com/w/page/10077130/T heories $\% 20 \mathrm{of} \% 20$ Education $\% 3 \mathrm{~A} \% 20 \% 20$ Essentialism. Diakes pada tanggal, 23 Juni 2014. 
such as math, natural science, history, foreign language, and literature form the foundation of the essentialist curriculum, elementary students receive instruction in skills such as writing, reading, measurement, and computers, ven while learning art and music, subjects most often associated with the development of creativity, the students are required to master a body of information and basic techniques, gradually moving from less to more complex skills and detailed knowledge, moreover, essentialists maintain that classrooms should be oriented around the teacher, who ideally serves as an intellectual and moral role model for the students.

Artinya bahwa aliran esensialis menekankankan pengetahuanpengetahuan dasar dengan berorientasi pada pendidik di kelas sebagai aktor intelektual karena memiliki kemampuan "mumpuni". Ini juga harus dilihat sebagai tantangan tersendiri bagi pendidik, yakni pendidik harus memiliki kemampuan lebih dan kompeten di dalam bidangnya. Bukan hanya keluasan pengetahuan melainkan kedalaman pengetahuan akan bidang yang digeluti.

Bahkan dalam manajemen kelas esensialis, menurut Summer Bret Kayla, bahwa:

... classroom management for the Essentialist holds a strong hand on the core values of discipline and having good morals. Also, they believe respect is a very important aspect. The essentialist classroom would be considered very strict and would have high expectations of excellent behavior". 39

Manajemen kelas untuk esensialis adalah memegang teguh nilai-nilai inti yakni disiplin dan memiliki moral yang baik. Mereka juga percaya bahwa menghormati merupakan aspek yang sangat penting. Ruang kelas esensialis sangat ketat dan memiliki harapan yang tinggi dari perilaku yang baik.

${ }^{39}$ www.ehow.com. Diakes pada tanggal, 23 Juni 2014. 


\section{Metode (Method)}

Metode yang ditawarkan dalam filsafat esensialisme adalah "penelitian dengan logika yang cermat." 40 Perhatikanlah bahwa dua hal ini, penelitian dan logika yang cermat merupakan dua cara yang berbeda dalam idealisme dan realisme. Kekayaan berpikir dari idealisme, yakni "kekuatan dalam abstraksi, kemampuan konseptual, logika, dll" diadopsi”; sejalan dengan itu, kekayaan berpikir dari realisme pun diadopsi, yakni "penelitian sebagai cara". Hal ini akan disokong oleh teori korespondensi.

\section{Pendidik (Teacher)}

Para esensialistik berpandangan bahwa "pendidik teladan adalah seorang yang mengerti kesusastraan dan ilmu pengetahuan, yang mengikuti perkembangan zaman modern dan yang telah mencapai tingkat seorang ahli dalam kompetensinya". ${ }^{41}$ Pemikiran ini khas idealistik. Pendidik dipandang sebagai "knower and thinker" atau pendidik menjadi rule model bagi peserta pendidik. Disamping pendidik menjadi rule model-nya peserta pendidik, para esensialitik juga tidak menafikan bahwa "peserta didik dipandang sebagai makhluk rasional yang menguasai fakta-fakta esensial dan keterampilan yang menunjang disiplin intelektualnya dalam rangka menyesuaikan diri dengan lingkungan secara fisik dan sosial". ${ }^{42}$

Dari pemikiran Knight dan Kneller, pendidik memainkan peran penting seperti yang disebutkan pada point ketiga yakni "teacher is the locus of classroom authority" atan "reestablishing the authority of the teacher in the classroom. Pendidik dituntut untuk mempersiapkan diri secara baik, baik dari segi kepribadian maupun penguasaan materi sehingga dapat mendesain kelas dengan lebih baik. Dengan catatan, pendidik harus menyadari bahwa yang belajar adalah peserta pendidik bukan pendidik, karena itu harus mempersiapkan sesuai kebutuhan peserta pendidik.

\section{Penilaian (Assessment)}

40 Boleh dikatakan bahwa gaya filsafat dan teori pendidikan esensialisme merupakan model "akomodatif" sebab mengakomodir, gaya idealisme dan realisme.

${ }^{41}$ Loc, cit.

${ }^{42}$ Loc, cit 
Untuk penilaian, esensialis sangat konsen dan pendidik memainkan peran yang sangat sentral. Arthur K. Ellis dalam Exempalrs of Curriculum Theory, mengatakan bahwa:

Assessment tends to take the form of letter grades, marked papers, standard test, report cards, and teacher judgment of pupil progress. Assessment, like planning, is largely in the hands of the teacher and other experts. Although formative assessment can and often does play a role in evaluation and diagnosis, emphasis is palced on sumative assessments ranging from end-of-term examinations to scores on standardized tests...the present-day standards movement and the push to test all children is evidence of the influence of essentialist educational though and practice. ${ }^{43}$

Dengan memperhatikan penilaian dalam konteks pendidikan esensialis, penilaian cenderung mengambil bentuk nilai angka, kertas penilaian, uji standar, rapor, dan penilaian pendidik untuk kemajuan peserta pendidik. Penilaian dalam sudut pandang esensialis seperti perencanaan, sebagian besar di tangan pendidik dan atau di tangan orang-orang yang berkompeten lainnya. Meskipun penilaian formatif dapat dan sering berperan dalam evaluasi dan diagnosis, penekanan ditempatkan pada penilaian sumative mulai dari akhir. Ini berarti bahwa pendidikan esensialis tidak hanya mengarahkan peserta pendidik untuk belajar secara disiplin, tetapi juga pendidik dan orang-orang atau pihakpihak yang berkompeten atau expert dituntut suatu kedisiplinan dalam penilaian atau assessment. Gerakan standar masa kini dan dorongan untuk menguji semua anak adalah bukti pengaruh pendidikan esensialis.

\section{Prinsip Pendidikan Esensialis (Ecuational Principle of Essentialist)}

Esensialisme tidak sepaham dengan perenealis dan progresifis. Dalam aliran esensialis, prinsip utama mereka adalah: "The school's first task is to teach bacic knowledge, leraning is hard work and requires disciple, the teacher is the locus of clssroom authority". ${ }^{4}$ Tiga prinsip esensialis dalam pendidikan bila dilihat berkaitan dengan kurikulum maka dapat didesain

43 Arthur K. Ellis, Exemplars of Curriculum Theory (New York: Eye on Education, 2004), 122.

${ }^{44}$ Knight, Philosophy and education, 109-111 
bertinggkat, mulai dari pengetahuan dasar, penerapan dari pengetahuan dasar dan bahwa pendidik sebagai pusat.

Meski dalam istilah yang berbeda namun sama dalam isi, Kneller juga berkata demikian, "the essentialist devote their main efforts to (a) reexmaning curricular matters, (b) distinguishing the essential and the nonessential in school programs, and (c) reestablishing the authority of the teacher in the classroom". 45

Sedangkan menurut Kneller, ada tiga prinsip dasar dalam pendidikan esensialis, yakni:

1) The school's firt task is to teach basic knowledge ${ }^{46}$ (tugas pertama sekolah adalah mengajarkan pengetahuan dasar). Bagi esensialist, education finds its center in the teaching and learning of the basic skill and subject matter that will, upon their mastery the student to function as a member of acivilized society. Pendidikan menemukan pusatnya pada pengajaran dan belajar dalam keahlian dasar dan "bahan-bahan" pokok. Dengan demikian, mereka akan menjadi bagian dari masyarakat yang berada.

2) Learning is hard work and requires disiplin. ${ }^{47}$ Belajar adalah pekerjaan yang berat dan butuh disiplin.

3) The teacher is the locus of classroom authority. ${ }^{48}$ Pendidik adalah wadah atau tempat dari otoritas kelas. Karena itu kaum esensialis memandang bahwa pendidik merupakan perwakilan dari orang yang "dewasa" atau "matang"- the teacher is the representative of the adult community, is in a position that demands respect. Jika tidak, "teacher has the right and responsibility to administer disciplinary measures that will lead to an atmosphere condusive to orderly learning-jika tidak maka pendidik bertanggungjawab untuk mendisiplinkan (bukan pendekan fisik yang mengarah pada kekerasan).

Kekuatan dan kelemahan filsafat esensialisme. Kekuatan dari teori ini adalah pada displin belajar yang tinggi dan penelitian. Namun, kelemahaman dari teori ini adalah bahwa kecenderungannya pada rasionalis. Hal ini juga yang dikemukakan Pazmiño bahwa bisa

\footnotetext{
45 Kneller, Introduction to the Philosophy of Education, 57.

${ }^{46}$ Knight, Philosophy and Education, 109.

47 Ibid., 110.

48 Ibid.
} 
"mengarah pada ekskulsivisme"49 rasionalistik bahkan "tidak berhubungan dengan pengalaman yang bersifat personal atau korporat". ${ }^{50}$ Padahal, logikanya seseorang yang sudah belajar, dapat menekuni bidangnya dan memiliki hubungan personal yang baik. Jika itu yang dipikirkan, maka itu bisa disebut idealisme dalam belajar.

\section{Filsafat Pendidikan Esensialis dalam Pendidikan Agama Kristen (PAK)}

Jika filsafat esensialisme diadaptasikan dalam teori pendidikan dan juga teori belajar, maka bagi pihak yang membahas materi pelajaran dapat mempertimbangkan kebutuhan siswa untuk dapat hidup produktif. Materi pelajaran tersebut bebas dari spekulasi dan perdebatan serta bebas dari bias politik dan agama.

Secara umum esensialisme adalah model pendidikan transmisi yang bertujuan untuk membiasakan siswa hidup dalam masyarakat masa kini. Konsep dasar pendidikan esensialisme adalah bagaimana menyusun dan menerapkan program-program esensialis di sekolah-sekolah.

Teori Pendidikan Esensialis yang Korelatif-aplikatif dalam PAK

Untuk bagian ini memang membutuhkan suatu sikap yang tegas dalam artian apakah harus "integrasi atau disintegrasi" 51 antara teori pendidikan esensialis dengan PAK. Penulis menyadari sepenuhnya akan perbedaan pendapat seputar hal ini. Namun mengingat keterbatasan "ruang," maka penulis memutuskan untuk melihat kedua hal ini dalam konteks keterhubungan metode dan bukan konten. Artinya, PAK yang nantinya dalam tulisan ini akan mencoba melihat prinsip pendidikan esensialis untuk selanjutnya melihat korelasinya dengan PAK. Sebab tidak mungkin integrasi isi atau konten sebab berbeda dalam sumber atau dasar konten. Hanya saja filsafat dan pendidikan menyediakan metode bagi PAK.

Dalam mencari hubungan yang korelatif-aplikatif antara esensialisme Pendidikan Agama Kristen, maka dimulai dari pemikiran

\footnotetext{
${ }^{49}$ Kneller, Introduction to the Philosophy of Education, 160.

${ }^{50} \mathrm{Ibid}$.

51 Tentu akan sangat terbantuk dengan esay dari James Riley Estep Jr, dalam, A Theology for Christian Education, (Neshville: B \& H Publishing Group, 1984). DALAM Bab II, What Makes Education Christian?
} 
bahwa, E.G. Homrighausen dan I.H. Enklar membangun sebuah kesepahaman melihat pendidikan agama yang berkembang di dunia Barat, tidak tepat dalam penggunaan istilahnya, khususnya di Indonesia sebagai konteks yang pluralistik ini. Kesepahaman yang dibangun E.G. Homrighausen dan I.H. Enklar tentang pendidikan Kristen atau PAK tersebut cenderung melihat pada sisi kejelasan dan ketegasan nilai pendidikan agama yang dibangun, yaitu Pendidikan Agama Kristen, bukan agama yang lain.

Dalam ulasannya, B.S Sidjabat ${ }^{52}$ menanggapi arah pendidikan Kristen, mengatakan bahwa "Pendidikan Kristen merupakan upaya ilahi dan manusiawi dilakukan secara bersahaja dan berkesinambungan untuk memberikan pengetahuan, nilai-nilai, sikap-sikap, keterampilan, sensitivitas, tingkah laku yang konsisten dengan iman Kristen.

Dalam bukunya, Sentot Sadono, ${ }^{53}$ kebanyakan dari mereka merasa jenuh dengan proses pendidikan yang mereka kerjakan. Alasan mendasarnya adalah mereka menemukan diri mereka sedang stagnan dan mengerjakan sesuatu yang monoton dari hari ke sehari dalam tanggung jawab pendidikan mereka.

Sungguh suatu alasan yang seharusnya tidak pernah terjadi dalam panggilan hidup sebagai pendidik. Howard Hendricks dalam Sadono, dalam bukunya Teaching to Change Lives menegaskan bahwa, "the effective teacher always teach from the overflow of a full life. The law of the teacher, simply stated, is this: If you stop growing today you stop teaching tomorrow". ${ }^{54}$

Karena itu, berdasarkan prinsip pendidikan esensialis yang dikemukakan Kneller dan Knight, maka akan dilihat korelasi yang aplikatif dari esensialis dalam PAK. Kneller maupun Knight masingmasing mencatat tiga prinsip yang intinya sama, seperti bagan di bawah ini.

52 B.S. Sidjabat, Strategi Pendidikan Kristen (Yogyakarta: Yayasan Andi Offset), 81.

53 Sentot Sadono, Psikologi Pendidikn Agama Kristen (Semarang: Sekolah Tinggi Teologi Baptis, 2011), 60-61.

54 Howard, Hendricks, Teaching to Change Lives (Colorado: Multnomah Books, 1987), 17. 


\begin{tabular}{|c|l|l|}
\hline No. & George Kneller & George Knight \\
\hline 1 & $\begin{array}{l}\text { Menjelaskan kembali } \\
\text { pokok-pokok kurikulum - } \\
\text { reexmaning curricular matters }\end{array}$ & $\begin{array}{l}\text { Tugas pertama sekolah adalah } \\
\text { mengajarkan pengetahuan } \\
\text { dasar - The school's firt task is to } \\
\text { teach basic knowledge }\end{array}$ \\
\hline 2 & $\begin{array}{l}\text { Membedakan yang } \\
\text { mendasar dan tidak } \\
\text { mendasar dalam program- } \\
\text { program sekolah- } \\
\text { distinguishing the essential and } \\
\text { the nonessential in school } \\
\text { programs }\end{array}$ & $\begin{array}{l}\text { Learning is hard work and requires } \\
\text { discipline }\end{array}$ \\
\hline 3 & $\begin{array}{l}\text { Merajar adalah pekerjaan yang } \\
\text { otoritas pendidik di kelas- } \\
\text { reestablishing the authority of the } \\
\text { teacher in the classroom }\end{array}$ & $\begin{array}{l}\text { Pendidik adalah wadah atau } \\
\text { tempat dari otoritas kelas- The } \\
\text { teacher is the locus of classroom } \\
\text { authority }\end{array}$ \\
\hline
\end{tabular}

Ketiga prinsip esensialis ini dalam tataran praksis PAK akan ditinjau dalam dua segi yakni pendidikan formal (yakni PAK) dan gereja (lokal). Karena itu sebelum masuk pada penjelasannya, penulis ingin mengetengahkan landasan berpikir teologis (teologi pendidikan dalam sudut pandang prinsip esensialis).

Tujuan umum pelayanan pendidikan gereja adalah bahwa semua orang tahu, dan mengembangkan kehidupan rohani yang dinamis, hubungan pribadi dengan Allah yang bertumbuh (Yoh. 17:3) dan ciptaan Tuhan. Pengetahuan ini dan hubungan harus didasarkan pada wahyu Allah dan keterbukaan diri dalam Kitab Suci dan berpusat sepenuhnya dan tegas dalam Yesus Kristus sebagai Tuhan dan Juruselamat (Yoh. 14:6; 17:07;. 2 Tim 3:16). Orang dari segala usia diaktifkan oleh Roh Kudus untuk merespon dalam iman, kasih, dan ketaatan sehingga masing-masing terus tumbuh sebagai anggota dari komunitas Kristen dan hidup di dunia sebagai wakil Kristus, sementara patuh dengan harapan 
kedatanganNya yang kedua. Tujuan pelayanan pendidikan adalah bahwa orang-orang menjadi peserta pendidik Yesus Kristus (Mat. 28:18-20), mempersiapkan diri untuk pekerjaan pelayanan dan sesuai untuk semakin serupa dengan Kristus (Ef. 4:11-16).

Ada perspektif diperluas di mana pusat-pusat pendidikan Kristen di kedua Firman Allah yang hidup (Kristus) dan Firman Allah yang tertulis (Alkitab). Hal ini dapat mengurangi bahaya untuk gagal menghubungkan isi Alkitab dengan Kristus yang hidup dan kehidupan orang.

Pendidikan Kristen haruslah berpusat pada Allah atau boleh dikatakan metafisika pendidikan Kristen berpusat pada Allah, karena itu:

Kurikulum. Seperti yang disampaikan oleh Kenneth O. Gangel dalam esaynya "the definitive chracter of Christian Education" bahwa "education for the early Hebrews focused on learning about God".55 Ini berarti desain kurikulum juga harus berpusat pada Allah. Kurikulum tentu berkaitan dengan bagaimana mendesain materi secara sistematis agar peserta pendidik dapat mengerti (tentu dengan metode yang sesuai). Dari sisi ini, sumbangsih yang diberikan esensialisme bagi PAK adalah:

Alkitab sebagai sumber utama PAK. Jika kita menyetujui pernyataan Alkitab sebagai sumber PAK, maka dibutuhkan kedisiplinan dalam mempelajari dan menerapkannya. Dari segi pendidikan formal Kristen, desain kurikulum harus terformat dengan baik agar membentuk peserta pendidik yang disiplin dalam belajar. Pada tingkat gereja (lokal), desainya pun haruslah mendasar. Contoh di bawah inipun sudah termasuk di dalamnya tentang penguatan intelektual.

Misalnya: untuk tingkat mendasar (basic) kurikulum didesain seperti:

Pengetahuan Alkitab:

Standar Kompetensi: memiliki wawasan dan pengetahuan tentang alkitab, baik latarbelakang kitab, tujuan kitab, tema kitab, dll.

Kompetensi dasar: mengetahui dan memahami latar belakang, tujuan dan tema kitab; memahami dan menerapkan materi yang telah dipelajari.

Pokok-pokok doktrinal

55 Robert E. Clark, Lin Johnson, Allyn K. Sloat (ed), Christain Education. Foundations for the Futur (Chichago: Moody Publishers, 2014), 15. 


\section{SUMBANGSIH FILSAFAT EKSISTENSIALISME BAGI P.A.K. 45}

Standar Kompetensi: memiliki wawasan dan pengetahun tentang pokok doktrin Kristen.

Kompetensi dasar: mengetahui dan memperlihatkan keyakinannya tentang doktrin Kristen (misalnya: Kristus, dosa, dll)

Filsafat esensialisme menekankan keunggulan akademis, penguatan intelek, serta transmisi dan asimilasi dari sekaian mata pelajaran yang wajib sifatnya". Esensialis percaya bahwa ada inti umum pengetahuan yang perlu sampaikan kepada siswa dalam cara yang sistematis dan penuh disiplin. Dari segi akademis atau penguatan intelek adalah pada sisi desain kurikulum baik di tingkat formal.

Pendidik. Para esensialistik berpandangan bahwa "pendidik teladan adalah seorang yang mengerti kesusastraan dan ilmu pengetahun, yang mengikuti perkembangan zaman modern dan yang telah mencapai tingkat seorang ahli dalam kompetensinya". Pemikiran ini khas idealistik. Pendidik dipandang sebagai "knower and thinker atau pendidik menjadi rule model bagi peserta pendidik. Disamping pendidik menjadi rule model-nya peserta pendidik, para esensialitik juga tidak menafikan bahwa "peserta didik dipandang sebagai makhluk rasional yang menguasai fakta-fakta esensial dan keterampilan yang menunjang disiplin intelektualnya dalam rangka menyesuaikan diri dengan lingkungan secara fisik dan sosial". Dari pemikiran Knight dan Kneller, pendidik memainkan peran penting seperti yang disebutkan pada point ketiga yakni "teacher is the locus of classroom authority" atau "reestablishing the authority of the teacher in the classroom.

Dalam korelasi-aplikatif ini, pendidik Kristen adalah model berharga bagi peserta pendidik (juga jemaat di tingkat gereja lokal) bahwa Kristus adalah kenyataan hidup dalam hidupnya (1 Korintus 11:1). Alkitab mengajarkan dan menekankan hubungan pribadi antara pendidik dan peserta pendidik. Kebenaran yang diajarkan melalui materi dan kehidupan akan memberikan pengaruh yang besar. Kompetensi dan keunggulan diperlukan dalam usaha mereka untuk mencerminkan teladan Kristen.

Kristus sebagai pendidik telah menjadikan dirinya sebagai role model bagi peserta pendidik-peserta pendidik-Nya. Ia menjadikan diri-Nya sebagai pusat bahkan di dalamnya kita dapat melihat dan meniru sikap kedisiplinan Yesus. Misalnya, Yesus secara berkelanjutan dan penuh disiplin, "pada waktu pagi-pagi benar, Ia berdoa"; Ia disiplin dalam 
melakukan penginjilan, Ia disiplin dalam mengajar dan mepeserta pendidikkan peserta pendidik-peserta pendidik-Nya.

Karena itu, pendidik harus tahu apa yang ia akan ajarkan, pengetahuan yang sempurna harus berdampak pula pada pengajaran yang sempurna. Reaksi awal yang harus dibangun adalah pertama-tama tentu memberatkan kepada posisi pendidik yang bersangkutan. Pendidik bertanggung jawab sepenuhnya terhadap kompetensi dirinya, keahlian dirinya, serta segala hal menyangkut kesiapan dirinya baik mental maupun spiritualnya. Maka dari itu, seorang pendidik harus bijak membangun kapasitas hidupnya, seperti apa yang Howard Hendricks pikirkan dalam perjalananan kehidupan seorang pendidik yaitu, "think of this way, as long as you live, you learn; and as long as you learn, you live".

Penilaian. Dengan memperhatikan penilaian dalam konteks pendidikan esensialis, penilaian cenderung mengambil bentuk nilai angka, kertas penilaian, uji standar, rapor, dan penilaian pendidik untuk kemajuan peserta pendidik. Penilaian dalam sudut pandang esensialis seperti perencanaan, sebagian besar di tangan pendidik dan atau di tangan orang-orang yang berkompeten lainnya. Meskipun penilaian formatif dapat dan sering berperan dalam evaluasi dan diagnosis, penekanan ditempatkan pada penilaian sumative mulai dari akhir. Ini berarti bahwa pendidikan esensialis tidak hanya mengarahkan peserta pendidik untuk belajar secara disiplin tetapi juga pendidik dan orangorang atau pihak-pihak yang berkompeten atau expert dituntut suatu kedisiplinan dalam penilaian atau assessment. gerakan standar masa kini dan dorongan untuk menguji semua anak adalah bukti pengaruh pendidikan esensialis.

Dalam korelasi-aplikatifnya, untuk pendidikan formal, sekolah dapat menerapkannya secara utuh. Maksudnya adalah, range penilaian harus dibuat atau ditentukan, harus ada portofolionya, dan pendidik harus membuat penilaian berkaitan dengan perkembangan belajar peserta pendidik. Persoalan yang muncul adalah pendidik tidak jujur dalam penilaian atau pendidik tidak disiplin dalam melakukan penilaian. Tentu ini akan mencapai tujuan yang ditentukan.

Dalam konteks praksis (gereja), Yesus telah memberikan contoh tentang hal penilaian. Meski Yesus tidak membuat range nilai (secara tertulis), namun Yesus telah membuat penilaian berkaitan dengan 
perkembangan spritual yang dalam hal ini Yesus menggunakan metode peserta pendidikan. Sebagai contoh, dalam catatan Injil sinoptik, Yesus berkata kepada peserta pendidik-peserta pendidik-Nya, "jenis ini hanya dapat diusir dengan doa dan puasa" atau "hai kalian orang-orang yang kurang iman". Yesus sebagai pendidik bagi peserta pendidik-peserta pendidik-Nya tahu perkembangan dan pertumbuhan spiritual mruidpeserta pendidik-Nya.

Dengan memperhatikan kurikulum, manajemen kelas, metode, pendidik dan penilaian maka semuanya ada dalam proses pendidikan. Proses pendidikan yang berkualitas (mengikuti setiap tahap-tahap manajerial pendidikan yang benar, mulai dari penerimaan, proses dan keluaran) akan menghasilkan keluaran atau out put yang berkualitas.

Bagi orang Kristen, dan dalam lingkup Pendidikan Kristen, mendengar pendidikan yang berkualitas mungkin orang Kristen mengaitkannya dengan lembaga-lembaga pendidikan Kristen yang sudah punya "nama" atau sudah lama "berdiri". Dalam hemat penulis, berkualitas atau tidak bukan pada "lamanya" melainkan pada proses pendidikan yakni proses manajerial. Proses manajerial yang baik menuntut penyelenggara menerapkan prinsip-prinsip manajemen, misalnya dalam konteks kini adalah penerapan Total Quality Management in Education. ${ }^{56}$ Ini penting jika ingin menghasil keluaran yang berkualitas.

Lulusan dapat dipahami sebagai kastemer primer yang telah memahami dan mangahayati sekolah secara utuh. Jasa sekolah dikelompokkan atas lima komponen ${ }^{57}$ utama yakni: 1) Jasa kurikuler; 2)

${ }^{56}$ Noh, Boiliu, TQM dalam Pendidikan Kristen. Jurnal Stulos, STT Bandung. Bagian abstrak: Dunia pendidikan harus menyambut baik dan menerapkan TQM dalam pendidikan sebagai bagian dari keinginan pencapaian mutu baik oleh internal customer maupun external customer. Di mana mutu sebagai "subjek" yang diacu dan dikontrol. Hal ini tentu dapat ditempuh dengan menerapkan metode-metode pendekatan yang sesuai dalam TQM. Badingkan dengan, Edward, Sallis, Total Quality Management in Education-Manajemen Mutu Pendidikan. Terj. (Yogyakarta: IRCiSoD, 2010).

${ }^{57}$ Jasa kurikuler, merupakan pelayanan yang bersifat kurikuler seperti penyusunan kurikulum dan silabus, perencanaan dan pelaksanaan pembelajaran, evaluasi, dan bimbingan. Jasa administrasi, meliputi administrasi umum, akademis dan kesiswaan. Jasa kebijakan umum, berbagai pelayanan yang bersifat kebijakan umum terutama dilaksanakan oleh pimpinan sekolah. 
Jasa administrasi; 3) Jasa kebijakan; 4) Jasa ekstrakurikuler; 5) Jasa penelitian.

\section{KESIMPULAN}

Dari pemaparan di atas maka disimpulkan bahwa Filsafat Esensialisme memiliki prinsip dasar sebagai berikut: (1) Tugas pertama sekolah adalah mengajarkan pengetahuan dasar -The school's firt task is to teach basic knowledge. (2) Belajar adalah pekerjaan yang berat dan butuh disiplin- Learning is hard work and requires disiplin. (3) Pendidik adalah wadah atau tempat dari otoritas kelas- The teacher is the locus of classroom authority. Selanjutnya sumbangsihnya terhadap Pendidikan Agama Kristen dapat dilihat dalam tiga prinsip esensialisme seperti di atas dan dapat dilihat melalui: Kurikulum, Manajemen kelas, Metode, Pendidik dan Penilaian

NOH IBRAHIM BOILIU adalah seorang dosen sistematika di STT Bethel The Way, Jakarta. Memperoleh gelar Sarjana Teologi (S.Th) dari STT Sangkakala, dan Magister Teologi (M.Th) dari STT Berita Hidup Surakarta. Sekarang sedang studi doktoral di STT Cipanas.

Sedangkan jasa ekstrakurikuler merupakan pelayanan dalam pengembangan kesiswaan di luar kegiatan kurikuler, tetapi mendukung kegiatan studi. 